3-1-2021

Pregnancy after embolization for arteriovenous malformation: An uncommon successful outcome

Arshia Javed

Sana Sheikh

Follow this and additional works at: https://ecommons.aku.edu/ pakistan_fhs_mc_women_childhealth_obstet_gynaecol

Part of the Female Urogenital Diseases and Pregnancy Complications Commons, and the Obstetrics and Gynecology Commons 


\title{
Pregnancy after embolization for arteriovenous malformation: An uncommon successful outcome
}

\author{
Arshia Javed1', Sana Sheikh²
}

\begin{abstract}
Uterine arteriovenous malformation (AVM) is an uncommon but fatal condition and can cause bleeding from abnormal connection between artery and vein. Pregnancy after embolization of uterine AVM is very uncommon, and there are increased risks of spontaneous abortion and growth retardation. We report a case of pregnancy after bilateral uterine artery embolization for AVM and its successful outcome.
\end{abstract}

Keywords: Uterine artery embolization, conception, pregnancy.

\section{DOI: https://doi.org/10.47391/JPMA.246}

\section{Introduction}

Uterine arteriovenous malformation (AVM) is an uncommon but fatal condition responsible for bleeding from vessels which are connected abnormally, usually arteries and veins are connected by fistula. ${ }^{1}$ The AVM can be congenital or acquired. Congenital uterine AVM arises from embryological developmental abnormality in vascular structure and abnormal communications between artery and vein. ${ }^{2}$ Acquired AVM arises due to uterine curettage, trophoblastic disease, endometrial cancer and infection. ${ }^{3}$ Angiography is the gold standard test for the diagnosis of AVM. ${ }^{2}$ Angiography is an invasive technique that helps to confirm the diagnosis by identifying the AVMs as complex tangle of vessels supplied by large feeding vessels, ${ }^{2}$ but nowadays colour Doppler ultrasound provides reliable diagnosis. The treatment options for AVM are either surgical with hysterectomy or uterine artery ligation, which have been used previously. Currently uterine artery embolization (UAE) is becoming more acceptable because of its capacity to preserve the reproductive capability. ${ }^{4}$ Pregnancy after embolization of uterine AVM is very uncommon. ${ }^{5}$ The first successful pregnancy case after embolization of uterine artery was reported by Chapman and Lutz in 1985.6 There are increased risks of spontaneous abortion and growth retardation due to poor vascularisation which disrupt the placental development and maternal-foetal blood flow at

1Department of Obstetrics and Gynaecology, The Aga Khan Hospital for Women, Karachi, Pakistan; 2Department of Obstetrics and Gynaecology, The Aga Khan University Hospital, Karachi, Pakistan.

Correspondence: Arshia Javed. e-mail: drarshiajaved@yahoo.com the treated area. Hyper selective embolization which only occlude feeding vessels of AVM and preserve other vessels, improves the pregnancy outcome. We report the case of a patient who became pregnant after bilateral uterine artery embolization for AVM and her pregnancy outcome. To the best of our knowledge no local case has been reported regarding pregnancy after AVM treatment. The institutional Ethical review committee (ERC) approval was obtained. The written consent of the patient was taken for the publication

\section{Case Report}

A 21-year-old primipara was admitted through the clinic with a two-day history of heavy vaginal bleeding. She had suction evacuation at eight weeks of gestation due to missed miscarriage on February 2017 and since then she had multiple episodes of vaginal bleeding. Her Doppler ultrasound revealed loss of endometrial-myometrial interface which confirmed the diagnosis of AVM. (Figure). Her bilateral uterine artery embolization was performed by interventional radiologist at the Aga Khan University Hospital, Karachi in March 2017, the patient remained stable after the procedure. ${ }^{7}$ The patient conceived spontaneously 15 months after embolization. She had her first antenatal visit at 16th weeks of gestation in clinic at The Aga Khan hospital for women Garden in December 2018. Her routine antenatal screening tests were normal except for haemoglobin which was $7.8 \mathrm{~g} / \mathrm{dl}$ with haematocrit (Hct) $25.6 \%$. Her serum ferritin was $5.8 \mathrm{ng} / \mathrm{ml}$, which confirmed the diagnosis of iron deficiency anaemia. Iron infusions were given and the haemoglobin level rose

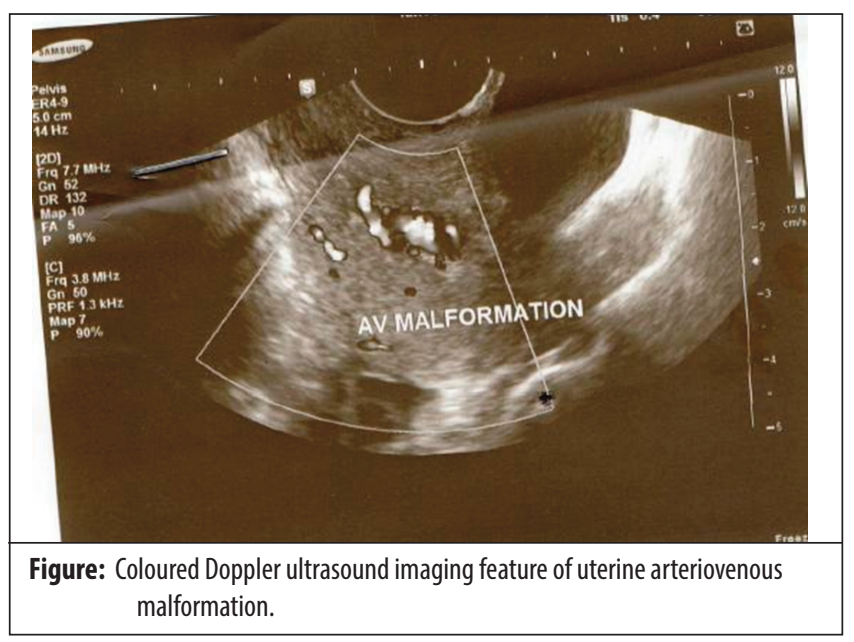


to $10.1 \mathrm{~g} / \mathrm{dl}$. All her antenatal scans showed appropriate foetal growth. At 39 weeks of gestation the patient came with labour pains, she opted for spontaneous progress of labour. After three hours of labour, spontaneous rupture of the membranes occurred and grade ii meconium stained liquor was observed. Her foetal cardiotocographic trace (CTG) showed variable decelerations. Emergency caesarean section was performed in view of non-reassuring CTG trace. She delivered a male baby on May 2019 weighing $3.7 \mathrm{~kg}$ with Apgar score 8 in 1 minute and 9 in 5 minutes. The placenta was removed; estimated blood loss was $500 \mathrm{ml}$. The patient was discharged on second post-operative day in stable condition, and stitches were removed on seventh post-operative day. To date the patient and her baby are well.

\section{Discussion}

Uterine AVM are very uncommon lesions due to arteriovenous shunts between myometrial arteries and veins. 2 Pregnancy after uterine artery embolization for AVM is very uncommon. ${ }^{5}$ A study by Barral et al showed that out of 12 women who had uterine artery embolization, only three conceived and only one pregnancy reached term. ${ }^{8}$ The fertility rate is lower after embolization, which is due to ovarian insufficiency or endometrial atrophy. The National Institute of Health and Care Excellence (UK) guideline 2010 states that patients who want to become pregnant should be explained the uncertain effects of UAE on fertility. ${ }^{1}$ The Royal College of Obstetricians and Gynaecologists guidelines 2013 state poor fertility evidence after UAE, so it should be performed after discussion with the women who wish to become pregnant in future. ${ }^{9}$ The risks of complications during pregnancy after UAE are abortion, placenta previa and morbid adherence of placenta. ${ }^{10}$ There is also increased rate of caesarean section, postpartum bleeding and foetal growth restriction. ${ }^{1}$

\section{Conclusion}

The reported case demonstrated that uterine AVM embolization in symptomatic patient not only resolved the symptoms but was also followed by spontaneous conception, pregnancy to term without any antenatal, intrapartum and post-natal risk to mother. Foetal outcome was also favourable.
Disclaimer: None.

Conflict of Interest: None.

Funding Sources: None.

\section{References}

1. Guida M, Maffucci D, lannuzzi G, Giordano M, Luciano G, Di Benedetto $L$, et al. Successful pregnancy after uterine artery embolization for uterine arterovenous malformation: a rare case report. Int J Womens Health 2018;10:745-50. doi: 10.2147/IJWH.S182131.

2. Chen Y, Wang G, Xie F, Wang B, Tao G, Kong B. Embolization of uterine arteriovenous malformation. Iran J Reprod Med 2013;11:159-66.

3. Calzolari S, Cozzolino M, Castellacci E, Dubini V, Farruggia A, Sisti G. Hysteroscopic Management of Uterine Arteriovenous Malformation. JSLS 2017;21:e2016.00109. doi: 10.4293/JSLS.2016.00109.

4. Maleux G, Timmerman D, Heye S, Wilms G. Acquired uterine vascular malformations: radiological and clinical outcome after transcatheter embolotherapy. Eur Radiol 2006;16:299-306. doi: 10.1007/s00330005-2799-5.

5. Delotte J, Chevallier P, Benoit B, Castillon JM, Bongain A. Pregnancy after embolization therapy for uterine arteriovenous malformation. Fertil Steril 2006;85:228. doi: 10.1016/j.fertnstert.2005.06.058.

6. Chapman DR, Lutz MH. Report of a successful delivery after nonsurgical management of a choriocarcinoma-related pelvic arteriovenous fistula. Am J Obstet Gynecol 1985;153:155-7. doi: 10.1016/0002-9378(85)90102-4.

7. Javed A, Chander R, Hoodbhoy Z. Uterine Arteriovenous Malformations after Suction Evacuation of Missed Miscarriage. J Coll Physicians Surg Pak 2018;28:s33-4. doi: 10.29271/jcpsp.2018.03.S33.

8. Barral PA, Saeed-Kilani M, Tradi F, Dabadie A, Izaaryene J, Soussan J, et al. Transcatheter arterial embolization with ethylene vinyl alcohol copolymer (Onyx) for the treatment of hemorrhage due to uterine arteriovenous malformations. Diagn Interv Imaging 2017;98:415-21. doi: 10.1016/j.diii.2016.09.003.

9. Karlsen K, Hrobjartsson A, Korsholm M, Mogensen O, Humaidan P, Ravn P. Fertility after uterine artery embolization of fibroids: a systematic review. Arch Gynecol Obstet 2018;297:13-25. doi: 10.1007/s00404-017-4566-7.

10. Soeda S, Kyozuka H, Suzuki S, Yasuda S, Nomura Y, Fujimori K. Uterine artery embolization for uterine arteriovenous malformation is associated with placental abnormalities in the subsequent pregnancy: two cases report. Fukushima J Med Sci 2014;60:86-90. doi: 10.5387/fms.2013-13. 